\title{
Sidoine Séguier de Saint-Brisson, Idylles françaises suivies de Ariste ou les charmes de l'honnêteté
}

\section{Elena Aschieri}

\section{(2) OpenEdition}

1 Journals

\section{Edizione digitale}

URL: http://journals.openedition.org/studifrancesi/8937

DOI: 10.4000/studifrancesi.8937

ISSN: 2421-5856

\section{Editore}

Rosenberg \& Sellier

\section{Edizione cartacea}

Data di pubblicazione: 1 octobre 2008

Paginazione: 463

ISSN: 0039-2944

\section{Notizia bibliografica digitale}

Elena Aschieri, «Sidoine Séguier de Saint-Brisson, Idylles françaises suivies de Ariste ou les charmes de I'honnêteté», Studi Francesi [Online], 155 (LII | II) | 2008, online dal 30 novembre 2015, consultato il 13 janvier 2021. URL: http://journals.openedition.org/studifrancesi/8937 ; DOI: https://doi.org/10.4000/ studifrancesi.8937

Questo documento è stato generato automaticamente il 13 janvier 2021.

\section{(c) (1)}

Studi Francesi è distribuita con Licenza Creative Commons Attribuzione - Non commerciale - Non opere derivate 4.0 Internazionale. 


\title{
Sidoine Séguier de Saint-Brisson, Idylles françaises suivies de Ariste ou les charmes de l'honnêteté
}

\author{
Elena Aschieri
}

\section{NOTIZIA}

SIDOINE SÉGUIER DE SAINT-BRISSON, Idylles françaises suivies de Ariste ou les charmes de l'honnêteté, édition critique par Frédéric S. Eigeldinger, Paris, Champion, 2006, pp. 222.

Il volume contiene due opere di Saint-Brisson, la prima delle quali, le Idylles, era fino ad oggi inedita mentre la seconda, Ariste ou les charmes de l'honnêteté, fu pubblicata nel 1764. Si tratta di testi che la critica letteraria ha ignorato ma che, in realtà, come ben sottolinea F. G. Eigeldinger, sono degni di attenzione. Due essenzialmente le ragioni: sono la testimonianza della forte influenza che le Idylles et poème champêtres dello svizzero Salomon Gessner ebbero in Francia nella seconda metà del Settecento e hanno offerto a Rousseau l'opportunità di esprimersi sul genere dell'idillio. Il marchese di Saint-Brisson chiese infatti più volte commenti e consigli sui suoi scritti al Ginevrino. Dalla corrispondenza tra i due, si possono così cogliere le posizioni di Rousseau che in quegli stessi anni (1763 con precisione) pubblicava il Lévite d'Ephraim. Rousseau e Diderot saranno tra i primi a riconoscere il merito di Gessner e a favorire l'entusiastica accoglienza delle sue opere in Francia (Rousseau confesserà nella Préface al Lévite d'Ephraim, di aver imitato le immagini di Gessner). La corrispondenza tra Rousseau e Saint-Brisson rivela invece un Jean-Jacques molto critico nei riguardi del secondo. «Rousseau critique» (pp. 29-33) e «Rousseau censeur moral» (pp. 38-41) sono i titoli di due dei paragrafi dell'Introduction di Eigeldinger che mostrano, riproponendo in parte la corrispondenza, la censura dapprima letteraria e poi morale cui l'autore ginevrino sottopose il suo ammiratore. «Vos idylles sont une imitation et vous avez imité jusqu'au style [...] vous n'atteignez jamais le vôtre [...], vous croyez imiter et vous copiez [...], voyez si vous trouvez dans le Cantique des Cantiques rien qui fatigue ainsi les poumons 
[...] voilà une chute à se casser le cou» (p. 30) sottolinea Rousseau per quanto concerne la critica dello stile, e per la censura morale aggiunge: «Le métier d'auteur n'est bon que pour qui veut servir les passions des gens qui mènent les autres, mais pour qui veut sincèrement le bien de l'humanité c'est un métier funeste [...] si vous n'avez qu'une mauvaise tête ou qui pis est votre cœur vous conduit mal, je ne veux conserver de liaison qu'avec des gens dont la tête et les cœurs soient sains» (pp. 39 e 41). È questo solo un piccolo assaggio del tono e del contenuto delle epistole rousseauiane. Anche se questa è l'opinione di Rousseau, i testi proposti da questa edizione, come mostra Eigeldinger e come abbiamo detto, posseggono una loro effettiva originalità, che la critica ha ingiustamente ignorato. Le due opere Idylles françaises (pp. 49-113) e Ariste ou les charmes de l'honnêteté (pp. 115-167) sono seguite dalle rispettive ricche Notes (pp. 169-195 e 197-204), da due Annexes (pp. 205-211) e da una completa ed aggiornata Bibliographie (pp. 213-216). 